\title{
Clinical practice in occupational therapy for treatment of concussion in schoolboys: An integrative review
}

\author{
*Faye Sinnett, BSc OT (Wits); MSc OT (Wits). http://orcid.org/0000-000 I-569 I-85 I 3 \\ Lecturer, Dept. of Occupational Therapy, School of Therapeutic Sciences, Faculty of Health Sciences, University of the \\ Witwatersrand.
}

\section{Denise Franzsen, BSc OT (Wits); MSc OT (Wits; DHT (UP); PhD (Wits). http://orcid.org/0000-000 I-8295-6329}

Sessional Senior Lecturer, Dept. of Occupational Therapy, School of Therapeutic Sciences, Faculty of Health Sciences, University of the Witwatersrand.

Rugby in South Africa is one of the fastest growing contact sports and schoolboys competing in rugby will sustain injuries such as concussions. Concussion protocol regulations indicate that young players be removed from play and training for two weeks as there are many misconceptions about the long-term implications of concussion. Concussion has been shown to impact on cognitive functioning and the ability to perform at school. Occupational therapy has a role in the intervention of occupational performance post-concussion in learners playing this contact sport.

A clinical practice framework to provide guidelines for the occupational therapy intervention for schoolboy rugby players post-concussion in the South African setting is presented. The framework was based on the occupations, client factors, performance skills, performance patterns and context and environments in the Occupational Therapy Practice Framework III (OTPF III). Screening assessment including the learners, parents and teachers were suggested to determine the use of specific occupational performance assessments in education, social participation, activities of daily living and rest and sleep as well as client factor assessments to determine the outcomes of concussion. Intervention guidelines include the occupational therapy process approaches for Create/Promote, Establish/Restore, Maintain, Modify (compensate) and Prevent with a focus on create/promote; or promotion of safety in rugby.

The assessments given in this framework are easily accessible in the South African setting and provide knowledge for all level of practitioners. The role of occupational therapy in reducing residual risks of concussion sustained while playing rugby at school and the long-term consequences of concussion on occupations needs to be researched further.

Key words: concussion, schoolboy concussion, concussion management, occupational therapy management

\section{INTRODUCTION}

South African rugby is one of the fastest growing contact sports in which approximately 204 II 9 players engage annually'. Rugby is also one of South Africa's top three sports that has a development programme for young players at all levels supported by the South African Rugby Union (SARU). The inclusion of more schools and schoolboys in rugby via the Vuka programme initiated in $2008{ }^{2}$, means that many children and adolescents (ages 5 - 18 years) are engaging in rugby during their primary and secondary school years ${ }^{3}$. Learners competing in a full contact sport, such as rugby, are at a high risk for injuries. The varying rules ${ }^{4}$ based on the age of the players and, or developmental stage of playing the game have implications for the number and type of injuries that occur, and which may influence, not only the learners ability to play the sport but their overall occupational performance ${ }^{5}$. However, these injuries in learners are under-reported and the exact incidence and consequence of the injuries is not well known or documented ${ }^{6,7}$. The BokSmart programme in South Africa works extensively to improve the safety of players in rugby with documents on Return to play ${ }^{8}$, Management of spinal cord injuries ${ }^{9}$ and Skeletal development and associated risks ${ }^{10}$ to name a few. However, these documents do not alleviate the inherent risk of a contact sport.

It is estimated that approximately $28 \%$ of learners who play rugby will sustain an injury in a game or during practice in a season, with $24.6 \%$ of these injuries being concussions and fractures ${ }^{6}$. This means that in a squad of 22 players, approximately six players may sustain an injury and at least one injury will be a concussion. During a season, the danger of sustaining a concussion is high however, as described by Thornton et al., a greater risk is the risk of a second concussion and the cumulative effects these concussions may have on the developing brain".

Concussion protocol regulations put in place by SARU, indicate that any suspected case of concussion must be reported, and the player must be assessed by medical personnel ${ }^{12}$. However, literature emphasises a lack in reporting of concussion and symptoms by young players due to the implications of the injury, such as being removed for two weeks from play and training in accordance with the concussion protocols ${ }^{6,11-15}$. Not being available to play for two weeks may have significant implications for selection for school, provincial or national teams, as well as impacting on the ability of 
a team to win when a key player is removed. The decisions which children and adolescents make about reporting a concussion may also be influenced by the environment or peer pressures, rather than warnings from coaches and medical professionals about the consequences of such an injury ${ }^{6,16}$. Thus, concussions may not be reported and may also be missed as the effects of a mild concussion are not always immediately obvious. Concussion symptomology, severity and length of symptomology differ for each individual and therefore a single set, un-altering plan of management would be unrealistic 6 ,17,18.

The importance of learners following rugby concussion protocols has been highlighted ${ }^{\prime 2}$. The many misconceptions about the long-term occupational implications of concussion and the role of the occupational therapist in the management of concussion are not recognised and understood. It is often believed that affected cognitive functioning improves rapidly after concussion with no long term consequences ${ }^{19}$ but research has proven this is not true in every case ${ }^{12,14,20}$. The impact of concussion on cognitive functioning in learners as a result of a rugby injury has been shown to influence their ability to engage socially ${ }^{12,19}$ and affects their academic performance at school ${ }^{21,22}$. Schoolboy rugby players who have suffered more than one concussion during their time at school, are six times more likely to suffer another concussion while participating in the sport when compared to adults 6 . The need for appropriate education, intervention and rehabilitation for everyone (particularly children and adolescents who sustain a concussion) has been emphasised $^{5,21,22}$. The limited literature on the role of occupational therapy in the prevention of concussion prior to injury (policy contribution), the management of a concussion and return to rugby post-injury, has affected the contribution this profession is currently making to improving occupational performance post-concussion $n^{5,23}$ and is not documented in South Africa or in relation to rugby.

\section{Background to concussion and return to play in schoolboy rugby players}

Developmental changes in the brain appear to increase during adolescence ${ }^{24}$ and Giedd et al. ${ }^{24}$ describe an increase in white and grey brain matter during late childhood and adolescence. This increase depends on the individual's environment and activities and is critical to the development of motor skills, problem solving, language, abstract thinking as well as social and emotional skills $\mathbf{s}^{25}$. This is a period of significant pruning of the overproduction of synapses that occur in early childhood, as specific synapses are consolidated - in preparation for full development of the brain - in early adulthood. Sowell et al. ${ }^{26}$ indicates that the changes which occur in post-adolescent brains are continuous as their synaptic functioning is refined. This makes the developing brain more susceptible to damage caused by concussion ${ }^{24,25}$ which has been linked to more long-term changes in cognition and emotions ${ }^{14,27}$.

Physiological changes that occur following concussion include neuronal depolarization, release of excitatory neurotransmitters and a changed metabolism ${ }^{28}$ as a result of decreased blood flow, axonal injury and neuro-inflammation. Diffuse axonal injury is a form of injury which may occur as a result of concussion. These changes are seen within the white matter of the brain tissue and can result in altered die-back disconnection (early degenerative events in the injured neurons) and reorganisation of axons ${ }^{29,30}$. This results in long-term implications and more severe effects particularly to white matter unmyelinated fibres that are found in the developing brain ${ }^{29}$. Any disruption of this process due to injury can have consequences for the development and consolidation of cognitive skills such as decision making and problem solving , $^{5,29,30}$

In contact sport however, literature describes a culture of underreporting of concussion which occurs not only in rugby but also in sports such as ice hockey and American football ${ }^{13,31-34}$. The underreporting of concussion results in not only a premature return to play ${ }^{34}$ but may also increase the risk of secondary concussion and the impact of this on the brain ${ }^{10}$. A thorough understanding of the assessment and intervention is required post-concussion and is therefore essential to any medical personal managing a learner with concussion ${ }^{6}$. However, since the damage to the brain due to concussion is not always evident on a Computerized Tomography (CT) scan, Giedd et al. ${ }^{24}$ argue that self-reporting and coach assistance are vital in identifying deficits after concussion prior to returning to play.

At the ' 4 th International Conference on Concussion in Sport' in Zurich ${ }^{35}$ a 'Return to Play' was described as a graded programme based on a criteria-based checklist which is used to guide the return to engaging in the sport post-concussion ${ }^{36,37}$. While Swanson et al. ${ }^{38}$ recommended its use to guide children returning to play, Gardner et al. ${ }^{39}$ recommend the use of the International Rugby Boards (IRB) guide to 'Return to Play' as the prefered literature. Although there is not one definition of 'Return to Play' after concussion or one best protocol to follow, most researchers agree the term refers to the time it takes for all symptomology of the concussion to resolve before the learner resumes a graded training programme ${ }^{|4,35-4|}$.

There is however a lack of cost-effective, reliable, valid or objective assessments to evaluate the severity of concussion. This, paired with the underreporting of concussion, places learners at higher risk of secondary concussions and the associated complications of this ${ }^{10,12,33,42,43}$. Thus, the implementation of the 'Return to Play' protocol is affected by the subjective nature of the evaluation of the symptoms that indicate a learner should or should not return to complex training regimes and play. This also makes it difficult to determine the point at which recovery has actually occurred ${ }^{27}$ and when there are no longer changes in the biomechanical, neurochemical and metabolic components of the brain, post-concussion, ensuring it is safe to resume playing rugby ${ }^{7}$.

In South Africa SARU (through the national BokSmart programme) have developed standardised and progressive 'Return to Play' regulations to ensure the safety of learners and reduce the significant risk of secondary concussion ${ }^{8}$. The protocol emphasises no return to play on the same day and that the player must have complete rest for 24 hours which is in line with the suggestions proposed in the Consensus statement on concussion in sport which was developed at the $5^{\text {th }}$ international conference on concussion in sport held in Berlin, October 20168,44. Relative physical rest should last for at least two weeks before a Graduated Return To Play (GRTP) programme is instituted if the player is symptom free including a gradual increase in engagement with the game as well as contact with other players $8,37,38,40,45$.

The 'Return to Play' protocol requires professionally trained medical personnel to ensure an accurate assessment that is not biased by the pressure for a player to return to the sport for other reasons ${ }^{8}$. However, as a first concern, evidence highlight the difficulties that learners in developing countries may face accessing these post-concussion assessments $28,41,45,46$. These may include limited financial resources of the school or learner. The BokSmart 'Return to Play' Position statement8 also does not take this into account as they specify that a trained medical professional should perform this assessment. They do not make mention of difficulties experienced by under resourced schools and clubs who may not have access to 
these assessments or professional expertise. Coaches and coaching personnel may be able to provide screening on the side line for concussion, however, a coach may be more concerned about winning a match than the health of a single player thus reinforcing the culture of underreporting of concussions ${ }^{6}$.

This integrative review of the literature presents the alignment of the literature on occupational therapy in the management of sports-related concussion in children with the Occupational Therapy Practice Framework $\mathrm{III}^{47}$ to the post-concussive symptomology of paediatric rugby injuries to provide recommendations for the occupational therapy intervention for schoolboy rugby players in South Africa.

\section{METHODOLOGY}

The purpose of this paper was to complete an integrative literature review to synthesise representative literature on the role occupational therapists should play in the treatment of sports-related concussion in schoolboys. Important considerations that will be discussed in this integrative review are the implications of concussion on brain function and structure, how concussion and function are currently assessed and what the role of occupational therapists is in the management of concussion. A holistic conceptualisation of the topic was considered with clinical suggestions as to where interventions should be focussed. This review was based on research that is scientifically sound and clinically useful for occupational therapists in this emerging area of practice were provided ${ }^{48}$. The integrative literature review procedure includes five steps; these steps are: Problem identification, Literature Search, Data Evaluation, Data Analysis and Presentation. These five steps will be further explained below.

\section{Problem and variable identification}

The initial stage of the review process included a clear formulation of the problem that the review will address, including the variables in the study ${ }^{49}$. The need for a thorough problem identification stage including the variables of the study facilitates the subsequent stages as the researcher is able to identify what should be included or excluded ${ }^{49}$.

A concern with the 'Return to Play' protocol in schoolboys is that it does not describe the necessary 'return to occupation' or 'occupational performance' that also need to occur post-concussion. The long-term effects of concussion on occupational performance are currently not well defined but may result in permanent dysfunction $^{5,25}$. Learners may experience delays in intellectual and social development as well as decreased performance at school and in other activities. The impact of concussion on cognitive functioning can influence the ability of learners to engage socially with others due to increased aggression, depression and frontal lobe influences on personality and mood ${ }^{13,19}$ impacting their ability to engage in schoolwork and sport. Multiple concussions have been associated with increased difficulty in learning and cognitive problems while long-term effects may also include light and noise sensitivity, as well as visual and cerebellar dysfunction and sleep disturbances ${ }^{10,13,21}$.

Addressing the limitations in occupational performance falls within the scope of the occupational therapist ${ }^{23}$, which highlights the need for this profession to be part of the multidisciplinary team treating learners with post-concussion. The main aim of this team is to return the learner to school and the sports field safely, and as soon as possible. Thus, team members should be well versed in their roles in concussion management ${ }^{22}$. In the BokSmart protocols, occupational therapy is not mentioned as part of the trained medical personnel able to provide concussion assessments and intervention ${ }^{8}$.
Return to learning after concussion guidelines from the American Academy of Paediatrics also do not mention occupational therapists specifically, although the American Occupational Therapy Association (AOTA) has emphasised the role of occupational therapy in managing post-concussion syndrome ${ }^{25}$. The AOTA has provided evidence that occupational therapists should be involved in identifying and providing intervention to overcome barriers to full participation in everyday occupations including education and sport for learners who have suffered concussion.

Literature on the symptomology of concussion alluded to occupational dysfunction but there were only a few occupational therapy studies, and none had been completed in South Africa. The limited literature available on the role and practice guidelines for concussion management in occupational therapy has been published in developed in countries such as American, Australia and Canada ${ }^{4,23,50}$ and may be unrealistic for application in the South African context. This is due to the use of expensive standardised tests which are not freely available in South Africa, as well as not being standardised on the South African population. According to the literature, a few occupational therapy assessments can determine the current level of functioning in a learner with mild traumatic brain injury or concussion $^{5,25,51}$. These assessments (such as the Canadian Occupational Performance Measure ${ }^{52}$ ) should be used together with the findings from the neurophysiologist and the physicians. However, due to the constraints mentioned above, access to physicians and neurophysiologists may not be possible in the private or public health setting in South Africa.

The variables associated with the problem identification included: schoolboys, sports-related concussion and occupational therapy intervention (assessment or treatment). Concussion from other causes e.g. trauma or accidents were therefore excluded as was management from a health care profession that was not an occupational therapist.

\section{LITERATURE SEARCH}

The variables and problem identified in the problem identification stage highlighted the inclusions and exclusions for the literature search stage. For this study the following computer-based databases were searched: CINHAL, ERIC, Pubmed and EBSCOHOST with the following key terms: 'Rugby' and 'occupational therapy' and 'concussion'. In this study no grey literature was used and therefore all articles were sources from peer-reviewed journals published after 2010. Publication bias was addressed through two authors doing separate searches and ensuring all appropriate, articles available to the University of the Witwatersrand Library were included. Articles were excluded if they did not have sports-related concussion content or if they did not have occupational therapy as an intervention. After the exclusions and evaluations of the articles, four journal articles within the inclusion and exclusion criteria 49 were included into this integrative review ${ }^{5,25}$. See Table I (page 65).

\section{DATA EVALUATION}

Three of the four articles were written by occupational therapists $^{5,25,53}$ and one article ${ }^{53}$ was written by neuropsychologists but included function as a measure in their study. All four of the articles had a different research design, which included a scoping review ${ }^{53}$, a prospective repeated measure study ${ }^{52}$, a commentary ${ }^{5}$ and a case study ${ }^{25}$. Sang et al. ${ }^{50}$ was the only article that had active participants in the study whereas Finn and Waskiewicz ${ }^{25}$ was a case study on a single participant. Reed ${ }^{5}$ and van Heugten et al..$^{53}$ wrote articles based on literature and were not participant-based studies. The 
Table I: Articles which met the inclusion criteria for the integrative review

The role of early intervention in improving the level of activities and participation in youths after mild traumatic brain injury: a scoping review $^{53}$

An innovative approach to measuring youth concussion recovery: Occupational performance ${ }^{50}$

Sport-Related Concussion and Occupational Therapy: Expanding the Scope of Practice ${ }^{5}$

The Role of Occupational Therapy in Managing Post-Concussion Syndrome ${ }^{25}$

low number of articles indicates that there is little written about the role of occupational therapists in concussion management and furthermore, the number of studies currently being conducted with participants is very low. Literature that is available is therefore primarily based on previously published literature which indicates a need for further research in this area. The four articles which were selected by agreement of the researchers were then analysed.

\section{Data Analysis}

The content of the articles was coded, analysed and integrated with the Occupational Therapy Practice Framework III (OTPFIII) ${ }^{47}$ which guides the occupational therapy process and includes assessment and intervention in occupational therapy. Concepts from the literature were analysed according to Categories of Occupations, Client Factors, Performance Skills and Performance Patterns affected post-concussion. Based on the environmental categories represented in the OTPFIII, the occupational context was included. Intervention described in the literature for concussion in schoolboys was conceptualised according to the type of occupational therapy intervention (adaptation, advocacy, education etc.).

The alignment of the literature with the OTPFIII indicated that the assessment required post-concussion can be categorised according to the Categories of Occupations, Client Factors, Performance Skills, Performance Patterns, and Contexts and Environment in Table II (page 66).

\section{Presentation}

The most beneficial assessment skill of occupational therapists is their ability to make observations and clinically reason why they may be observing a specific difficulty and what categories of occupation this will affect. The use of multiple assessment tools such as interviews, standardised and non-standardised tests and observations allows the therapist to triangulate information and, together with the learner and their family, develop therapeutic goals and an intervention plan. Therapeutic intervention should follow a specific approach within the different categories of occupation.

As in any concussed population, an important consideration when completing assessments is that no in-depth assessment or intervention should begin prior to symptoms of the concussion having subsided, as learners require cognitive as well as physical rest post-concussion ${ }^{21}$. An intense assessment period may exacerbate symptoms that were resolving or increase the severity of current symptoms when activities - even assessment activities - are not introduced in a graded manner. This may be done over time to avoid cognitive fatigue which may impact on the learner's scores on test ${ }^{50}$.

The category of occupations that is affected according to the literature from most affected to least affected include: Education ( 4 articles), followed by Activities of Daily Living ( 3 articles), Rest and Sleep (3 articles), Social Participation (2 articles), and Instrumental Activities of Daily living (I article). One article described the play category of occupation ${ }^{5}$ and one article described the leisure category of occupation ${ }^{50}$, however the description of play and leisure were both centred on sport (engagement in and return to sport). For this study, sport was included under the occupation of education as it is assumed to be an extra mural which is listed in the education category of occupation in the OTPFIII ${ }^{54}$. As client factors, performance skills, performance patterns and contexts and environments are integrated into the category of occupation, they will be discussed within each category of occupation. This will include how the categories of occupations should be assessed and treated by occupational therapists (see Table III page 67).

\section{Education}

Education is significantly affected in the post-concussion phase due to the difficulties learners experience with information processing speed, attention, memory, judgement, decision making, impulsivity, visual perceptual skills, executive functioning, postural control, balance and psychomotor speed $13,17,27,55,56$.

Post-concussion schoolboy rugby players need to return to learning to ensure they are able to not only continue learning, but also to return to the game. A previously concussed learner may primarily have difficulty engaging with the material being taught in the classroom due to their distractibility and difficulties with processing skills. They may also have difficulties remembering what they are learning or making decisions in the classroom. Visual-perceptual difficulties may influence their ability to process written information or determine what and where they are learning on a page of text ${ }^{23}$ which may further be due to changes in their motor skills. A secondary factor affecting education is returning to learning too soon.

A learner who has sustained a concussion should only return to the learning environment once all symptomology has subsided, which may vary from a few days to a few weeks ${ }^{22}$. A learner who returns to the learning environment without the adequate rehabilitation may in fact exacerbate their previously subsided symptoms of concussion and may have more difficulties returning to school in the long term ${ }^{22}$.

A learner who is not able to return to school may feel isolated from friends and peers and an occupational therapist must consider the influence this may have on daily social participation. The assessment of the education category of occupation should therefore focus on the ability to cope with academic requirements (including changes in visual perceptual skills), sensory abilities including the requirements of the classroom and social requirements of the school environment.

For the learner whose symptoms of their concussion remain for longer than 2 weeks post- injury, staying away from school for up to three months may have greater implications on learning than returning prior to full subsided symptomology ${ }^{13}$. However, returning to the classroom may be overstimulating and the academic expectations may be excessive which may result in a learner being unable to engage with school activities. It is for this reason that adaptations/accommodations should occur both to the environment and academic expectations.

To return to school, client factors and performance skills such as attention span, ability to lay down new information and recall information on demand, executive functioning including decision making and problem solving and also physical difficulties such as postural control and balance difficulties, need to be improved. Therapy may be individual or group sessions with similar goals and aims. While intervention is occurring, a thorough under- 
Table II: Occupational performance affected post-concussion

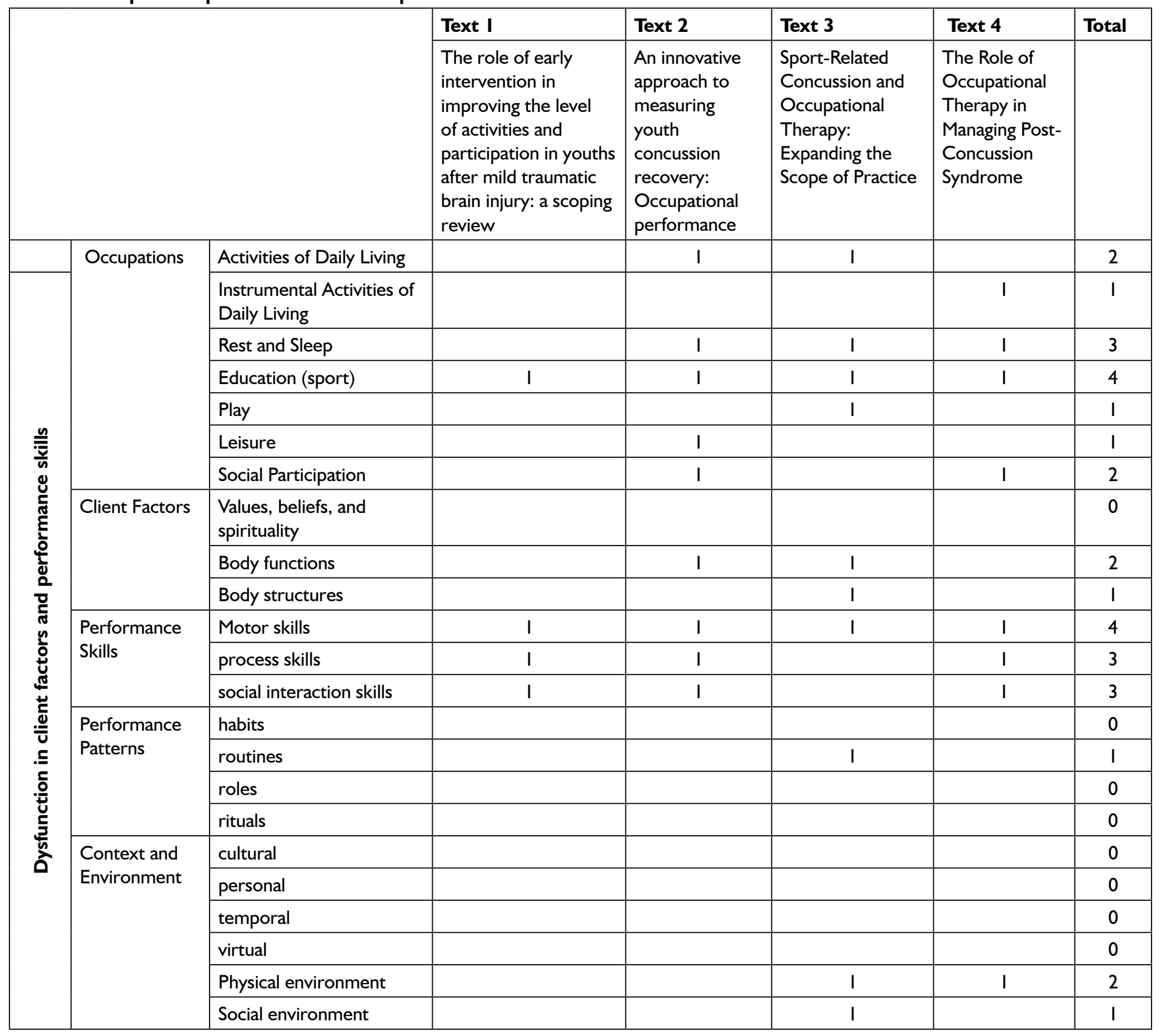

standing of the environment that the learner is returning to, as well as the staff in these environments is essential ${ }^{22}$. Adaptations/ accommodations to the classroom that may assist in the process of return to school may include: changes in the position of the learner to limit the effects of changes in light or artificial light, removal or replacement of materials on the walls to ensure that the learner is not unnecessarily distracted or to allow regular breaks and to return to the school environment for shortened periods of time ${ }^{23}$. Learners may also require adaptations/accommodations to the academic requirements expected of them not only in the classroom but also the homework requirements. Slow reintegration into the education process is required with respect to the amount of work required and they should be expected to catch up all their missed work over time and not on immediate return to $\mathrm{school}^{23}$. An increased time to be able to complete tests and exams may also be required to ensure the student can take breaks as needed. Adaptations / accommodations are often missed when learners do not present with a diagnosis of concussion but may suddenly perform worse in classroom activities, tests and exams ${ }^{13}$.

\section{Activities of Daily Living}

Three articles describe difficulties with Activities of Daily Living (ADLs) specifically feeding (deciding what to eat and eating it) and dressing $^{50}$. Difficulties with ADLs effects the ability to engage in all activities and engagement within their context and environment. Activities of daily living are fundamental activities that allow a person to engage and therefore there should be a focus on treating ADLs with post-concussion clients. Assessments and treatment should focus on the underlying client factors, performance skills and performance patterns which are affecting engagement in ADLs such as decision making and judgement.

\section{Rest and Sleep}

The neurological damage sustained during a concussion can result in: difficulties falling asleep, decreased length of sleep and poor quality of sleep; especially if there is damage to the hypothalamus and surrounding areas ${ }^{28}$. Difficulties with sleep can affect a learner's ability to concentrate in class, participate in activities and in receiving enough cognitive rest. It is therefore imperative as an occupational therapist to assess sleep preparation, participation and routine 
Table III: Intervention aligned with the Occupational Therapy Practice Framework III

\begin{tabular}{|c|c|c|c|c|c|c|}
\hline & & Text I & Text 2 & Text 3 & Text 4 & Total \\
\hline & & $\begin{array}{l}\text { The role of early } \\
\text { intervention in } \\
\text { improving the level } \\
\text { of activities and } \\
\text { participation in } \\
\text { youths after mild } \\
\text { traumatic brain } \\
\text { injury: a scoping } \\
\text { review }\end{array}$ & $\begin{array}{l}\text { An innovative } \\
\text { approach to } \\
\text { measuring youth } \\
\text { concussion } \\
\text { recovery: } \\
\text { Occupational } \\
\text { performance }\end{array}$ & $\begin{array}{l}\text { Sport-Related } \\
\text { Concussion and } \\
\text { Occupational } \\
\text { Therapy: } \\
\text { Expanding the } \\
\text { Scope of Practice }\end{array}$ & $\begin{array}{l}\text { The Role of } \\
\text { Occupational } \\
\text { Therapy in } \\
\text { Managing Post- } \\
\text { Concussion } \\
\text { Syndrome }\end{array}$ & \\
\hline \multirow{6}{*}{ 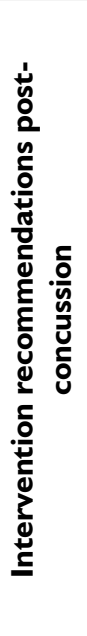 } & $\begin{array}{l}\text { Create, promote (health } \\
\text { promotion) }\end{array}$ & $\begin{array}{l}\text { education } \\
\text { programmes }\end{array}$ & $I$ & & & 1 \\
\hline & $\begin{array}{l}\text { Establish, restore } \\
\text { (remediation, restoration) }\end{array}$ & & $\mathrm{I}$ & 1 & 1 & 3 \\
\hline & Maintain & & & & & 0 \\
\hline & $\begin{array}{l}\text { Modify (compensation, } \\
\text { adaptation) }\end{array}$ & Rest & I & & 1 & 2 \\
\hline & & $\begin{array}{l}\text { Graded activity } \\
\text { procedures }\end{array}$ & I & & 1 & 2 \\
\hline & $\begin{array}{l}\text { Prevent (disability } \\
\text { prevention) }\end{array}$ & $\begin{array}{l}\text { Prevention } \\
\text { programmes }\end{array}$ & & & $I$ & I \\
\hline
\end{tabular}

especially in children and adolescents ${ }^{47,50}$ considering they require additional rest and sleep while recovering from a concussion to ensure there is no prolonged symptoms of concussion.

Intervention for rest and sleep should therefore focus on preparing for sleep. Limiting the use of technology after a certain time in the evening should be recommended and sleep should be reduced during the day to increase sleep at night. A therapist may be unable to treat sleep disturbances without the assistance of parents to ensure the learner is following recommendations adequately. This should be emphasised in the initial sessions.

\section{Social participation}

Social participation is necessary for learners to ensure they do not become isolated, which can lead to depression and anxiety ${ }^{23}$. A number of symptoms may influence their inability to engage in social participation, including decreased emotional regulation due to frontal lobe damage ${ }^{28}$, decreased balance and an encouraged decrease in the amount of time spent on cell phones and electronic devices ${ }^{57}$. To ensure a learner who sustained a concussion can engage in social participation in an appropriate manner, the occupational therapist needs to understand the client factor and performance skill demands that engaging socially has on the learner. The learner is required to attend to what their friends are saying and doing and remaining upright while engaging in communication. As well as be able to engage in conversations on social media including text and visual input. A learner returning to the school environment may have difficulties managing their emotions or responses to others. This may influence their relationships with peers and may lead to the learner feeling isolated from others further when returning to school.

As an occupational therapist, the aspects to consider would include what type of activities the learner engages in with peers during social participation as well as the setting and context of the social participation. Therapy should therefore focus on social interactions, appropriate behaviours for different situations and counselling specific to the occupation of social participation. This may include the learner's understanding of how to manage new social situations, the appropriate behaviour in specific situations and where there may be concerns. It is the role of the occupational therapist to educate not only the learner who sustained the concussion but also his teammates and friends. It may also be the role of the therapist to assist in the reintegration to the team ensuring the student is able to return to social participation ${ }^{5}$.

\section{Instrumental activities of daily living}

Post-concussion the use of electronic devices it is highly recommended that their use is limited. This is a major concern for many learners. This limited use of electronic devices affects a learner's ability to participate in communication management (the ability to use a cell phone and other devices) especially for learners who may be experiencing light sensitivity. These learners may feel isolated without the ability to communicate with friends and peers and often struggle significantly to remain off their cell phones. The most important aspect to contain cell phone usage is their understanding of themselves, their behaviours and the consequences thereof (insight). Learners need a thorough understanding of how communication devices may affect their symptoms and how the use of these devices may increase their concussion symptoms as well as possibly extending the amount of time it takes for recovery ${ }^{58}$.

\section{CONCLUSION}

The categories of occupation as described in the OTPF III align with the literature reporting on the effects of concussion in adolescents 
who play rugby. The assessment for concussion in this population described in the literature can be clearly linked to the OTPF III categories of occupation, client factors and performance skills. A further integration of the literature to the OTPF III based on the categories of occupation is the inclusion of the types of intervention required post-concussion, in line with health promotion, restorative/remediation, adaption or disability prevention focus of the OTPF III. The need for occupational therapy in the role as an educator, advocate and clinician are highlighted in this article. Although there is limited literature written on the role of occupational therapy in the treatment of concussion, the role should be highlighted. The need for occupational therapists to provide intervention with regards to concussion is important and the role of occupational therapists should be advocated for not only within our profession but with all professionals involved in the management of concussion.

\section{REFERENCES}

I. International Rugby Board. World Rugby Player Numbers, https://www.world.rugby/development/player-numbers?lang=en (2016, accessed 12 October 2018).

2. Hendricks $S$, O'Connor $S$, Lambert $M$, et al. Contact technique and concussions in the South African under-18 Coca-Cola Craven Week rugby tournament. Eur J Sport Sci. 2015; 15: 557 - 564. https://doi.org/10.1080/17461391.2015.1046192

3. Nel C, Grace J, Nel K, et al. Cumulative Mild Head Injury (CMHI) in schoolboy rugby players. African J Phys Heal Educ. 2015; 211 : $92-102$.

4. South African Rugby Union. South African Rugby Union Primary School Law Variations; 2018.

5. Reed N. Sport-Related Concussion and Occupational Therapy: Expanding the Scope of Practice. Phys Occup Ther Pediatr. 201 I; 31: 222 - 224. https://doi.org/10.3109/01942638.2011.5897।9

6. Kirkwood G, Pollock A, Ofori-Asenso R, et al. Systematic review of rugby injuries in children and adolescents under 21 years. Br J Sports Med. 20I5; 49: 511 - 519. https://doi.org/10.1 I36/bjsports-2014-093684

7. Graham R, Rivara F, Ford M, et al. Sports-Related Concussions in Youth: Improving the Science, Changing the Culture. Military Medicine. 2015; 180(2): 123 - 125

https://doi.org//0.7205/milmed-d-14-00516

8. BokSmart. BOKSMART POSITION STATEMENT: RETURN TO PLAY; 2009.

9. Dunn R. BokSmart: Medical management of suspected serious acute spinal cord injuries in rugby players. South African J Sport Med. 2017; 2I: 9 I - 96. https://doi.org/I0.17/59/2078-5I6x/2009/v2Ii3a294

10. Lambert M, Brown J, Forbes J. BokSmart 2010 skeletal development and the associated risk of catastrophic head, neck and spine injury. http://www.sarugby.co.za/boksmart/pdf/BokSmart 2010-Skeletal development the associated risk of catastrophic head, neck and spine injury.pdf (2010, accessed 24 October 2018).

II. Thornton A, Cox D, Whitfield K, et al. Cumulative concussion exposure in rugby players: Neurocognitive and symptomatic outcomes. J Clin Exp Neuropsychol. 2008; 30: 398 - 409. https://doi.org//0.1080/13803390701443662

12. South African Rugby Union. SARU Regulations for Concussion. SARU.

13. Beilinsohn T. Cumulative mild head injury in rugby : a comparison of cognitive deficit and postconcussive symptomatology between schoolboy rugby players and non-contact sport controls. Masters Thesis in Clinical Psychology, Rhodes University; 200 I. vital: 293I, http://hdl.handle.net/I0962/d I002440, Rugby football injuries, Head -- Wounds and injuries - Psychology, Head - Wounds and injuries - Complications, Brain damage.

14. Delahunty S, Delahunt E, Condon B, et al. Prevalence of and Attitudes About Concussion in Irish Schools' Rugby Union Players. J Sch Health. 2015; 85: 17 - 26. https://doi.org/10.1 I I //josh. 12219

15. Guskiewicz K, McLeod T. Pediatric Sports-related Concussion. PM\&R. 20II; 3: 353 - 364.

https://doi.org/10.1016/j.pmrj.2010.12.006

16. Hendricks $S$, O'Connor S, Lambert $M$, et al. Video analysis of concussion injury mechanism in under- 18 rugby. BMJ Open Sport Exerc Med. 2016; 2: e000053.

https://doi.org/10.1 I36/bmjsem-2015-000053

17. Steinberg L. Cognitive and affective development in adolescence. Trends Cogn Sci. 2005; 9: 69 - 74. https://doi.org/10.1016/j.tics.2004.12.005

18. McCrory P, Collie A, Anderson V, et al. Can we manage sport related concussion in children the same as in adults? Evidence based guidelines are required for the management of concussive injury in children. $\mathrm{Br} J$ Sports Med. 2004: 516 - 519. https://doi.org/10.1 I36/bjsm.2004.0148II

19. Guskiewicz K, Mcleod T. Clinical Review: Current Concepts Pediatric Sports-related Concussion. PM R. 20I I; 3: 353 - 364. https://doi.org/10.1016/j.pmrj.2010.12.006

20. Lueke L. High school athletes and concussions. J Leg Med. 20I I; 32: 483 - 501. https://doi.org/10.1080/01947648.201।.632710

21. Laubscher J, Dijkstra H, Strydom G, et al. Academic consequences of very mild and mild traumatic brain injuries in secondary school rugby players. African J Phys Heal Educ Recreat Danc. 2010; 16 : 22 I - 230. https://doi.org/10.43 I4/ajpherd.v16i2.5596 I

22. Halstead M, McAvoy K, Devore C, et al. Returning to Learning Following a Concussion. Pediatrics. 2013; 132: 948 - 957. https://doi.org/10.1542/peds.2013-2867

23. Master C, Gioia G, Leddy J, et al. Importance of 'return-to-learn' in pediatric and adolescent concussion. Pediatr Ann. 20I2; 4I: I - 6. https://doi.org/I0.3928/0090448I-20120827-09

24. Giedd J, Blumenthal J, Jeffries N, et al. Brain development during childhood and adolescence: a longitudinal MRI study. J Comput Assist Tomogr. 1999; 51 : 648 - 660. https://doi.org/10.1038/I3158

25. Finn C, Waskiewicz M. The Role of Occupational Therapy in Managing Post-Concussion Syndrome. Phys Disabil Spec Interes Sect Q. 2015; 38: I - 4.

26. Sowell E, Thompson P, Holmes C, et al. In Vivo Evidence for PostAdolescent Brain Maturation in Frontal and Striatal regions. Nat Neurosci. 1999; 2: 859 - 860. https://doi.org//0.1038/I3154

27. Field $M$, Collins $M$, Lovell $M$, et al. Does age play a role in recovery from sports-related concussion? A comparison of high school and collegiate athletes. https://pdfs.semanticscholar.org/0507/66bc2592 03bceb96 I 7ed6c734a26d4690405.pdf (2003, accessed 25 October 2018). https://doi.org//0.1067/mpd.2003.190

28. Toledo E, Lebel A, Becerra L, et al. The young brain and concussion: imaging as a biomarker for diagnosis and prognosis. Neurosci Biobehav Rev. 2012; 36: 1510 - 31. https://doi.org/10.1016/j.neubiorev.2012.03.007

29. Wang J, Hamm R, Povlishock J. Traumatic Axonal Injury in the Optic Nerve: Evidence for Axonal Swelling, Disconnection, Dieback, and Reorganization. J Neurotrauma. 20I I; 28: II85 - II98. https://doi.org/10.1089/neu.201 I. 1756

30. Ordookhanian C, Tsai K, Kaloostian S, et al. Diffuse Axonal Injury: A Devastating Pathology. In: Traumatic Brain Injury-Pathobiology, Advanced Diagnostics and Acute Management. IntechOpen. 2018. 
https://doi.org// 0.5772/intechopen.72828

31. Kilinc D, Gallo G, Barbee K. Mechanical membrane injury induces axonal beading through localized activation of calpain. Exp Neurol J. 2009; $219: 553-561$. https://doi.org//0.1016/j.expneurol.2009.07.014

32. Collins M, Grindel S, Lovell M, et al. Relationship Between Concussion and Neuropsychological Performance in College Football Players. JAMA. 1999; 282: 964 - 970. https://doi.org/10.1001/jama.282.10.964

33. Shuttleworth-Edwards A, Radloff S. Compromised visuomotor processing speed in players of Rugby Union from school through to the national adult level. Arch Clin Neuropsychol. 2008; 23: 51 I - 520. https://doi.org/10.1016/j.acn.2008.05.002

34. Bleakley C, Tully M, O'Connor S. Epidemiology of adolescent rugby injuries: a systematic review. J Athl Train. 20I I; 46: 555 - 565. https://doi.org// 0.4085// 062-6050-46.5.555

35. McCrory P, Meeuwisse W, Aubry M, et al. Consensus statement on concussion in sport: the 4th International Conference on Concussion in Sport held in Zurich, November 2012. Br J Sports Med. 200 I; 6: I - 3. https://doi.org/10.1097/jsm.0b013e31828b67cf

36. Rapetsoa $\mathrm{M}$. Cumulative mild head injury (CMHI) in contact sports:an evaluation of pre and post season cognitive profiles rugby players compared with non-contact sport controls at the University of Limpopo(Turfloop Campus). University of Limpopo. http:// ulspace.ul.ac.za/handle/I0386/I772 (20I5, accessed 6 June 20I8).

37. Marshall S, Spencer R. Concussion in Rugby: The Hidden Epidemic. J Athl Train. 200I; 36: 334 - 338,

http://www.ncbi.nlm.nih.gov/pubmed/I 2937506 (200I, accessed 14 June 2018).

38. Swanson E, Benefield B. Concussion-Return to Learn, Return to Play, and Cognitive Rehabilitation. https://www.alabamashaa.org/ files/Convention 2018/Handouts 2018/Swanson-Kimani-ConcussionRehab.pdf (20I7, accessed I 2 June 20I8).

39. Gardner A, Iverson G, Williams H, et al. A Systematic Review and Meta-Analysis of Concussion in Rugby Union. Sport Med. 20 I4; 44: 1717 - 1731. https://doi.org/10.1007/s40279-0|4-0233-3

40. Walker S. Concussion knowledge and return-to-play attitudes among subelite rugbyunion players. SouthAfrican JSport Med. 20I5;27:50-54. https://doi.org/10.17159/2413-3108/2015/v27i2a492

4I. Erlanger D, Kutner K, Barth J, et al. FORUM Neuropsychology of Sports-Related Head Injury: Dementia Pugilistica to Post Concussion Syndrome. Clin Neuropsychol. 1999; 13: 193 - 209. https://doi.org/10.1076/clin. 13.2.193.1963

42. Echemendia R, Giza C, Kutcher J. Developing guidelines for return to play: Consensus and evidence-based approaches. Brain Inj. 2015; 29: 185 - 194. https://doi.org/10.3109/02699052.2014.965212

43. McKeever C, Schatz P. Current Issues in the Identification, Assessment, and Management of Concussions in SportsRelated Injuries. Appl Neuropsychol. 2003; 10: 4 - II. https://doi.org/I0.1207/sI5324826an I00I_2

44. McCrory P, Meeuwisse W, Dvořák J, et al. Consensus statement on concussion in sport - the 5 th international conference on concussion in sport. Br J Sports Med. 2017; 51: 838 - 847.

45. Iverson G, Echemendia R, LaMarre A, et al. Possible Lingering Effects of Multiple Past Concussions. Rehabil Res Pract. 2012; 2012: I - 7. https://doi.org/10.1/55/2012/316575

46. Zillmer E. Sports-Related Concussions. Appl Neuropsychol. 2003; I0: I - 3. https://doi.org/I0.1207/s I5324826an I00I_I

47. American Occupational Therapy Association. Occupational therapy practice framework: Domain \& process 3rd edition. Am J Occup Ther. 2014; 68: SI - S48. https://doi.org/10.50I4/ajot.2014.682006
48. Torraco R. Writing Integrative Literature Reviews: Guidelines and Examples. Hum Resour Dev Rev. 2005; 4: 356 - 367. https://doi.org/10.1177//1534484305278283

49. Whittemore R, Knafl K. The integrative review: Updated methodology. J Adv Nurs. 2005; 52: 546 - 553. https://doi.org/10.1 I I I/j.1365-2648.2005.0362I.x

50. Sang R, Vawda $Y$, Greenspoon D, et al. An innovative approach to measuring youth concussion recovery: Occupational performance. $\mathrm{Br} J$ Occup Ther. 2019; 0: 1 - 8. https://doi.org/10.1016/j.apmr.2018.09.010

5I. Case-Smith J, O' Brien JC. Occupational therapy for children. Mosby Toronto; 2015.

52. Law M, Baptiste S, Carswell A, et al. Canadian occupational performance measure: COPM. CAOT Publ. ACE; 1998. https://doi.org/10.1037/t7/986-000

53. van Heugten C, Renaud I, Resch C. The role of early intervention in improving the level of activities and participation in youths after mild traumatic brain injury: a scoping review. Concussion. 2017; 2: CNC38. https://doi.org/10.2217/cnc-2016-0030

54. Occupational therapy practice framework: Domain and process (3rd ed.). FRAMEWORK : Domain \& Process. Am J Occup Ther 2014; 68: SI - S5I. https://doi.org/I0.50I4/ajot.20I4.682006

55. Howell D, Osternig L, Van Donkelaar P, et al. Effects of concussion on attention and executive function in adolescents. Med Sci Sports Exerc. 2013; 45: 1030 - 1037. https://doi.org/10.1249/mss.0b013e3182814595

56. Kirkwood M, Yeates K, Taylor G, et al. Management of Pediatric Mild Traumatic Brain Injury: A Neuropsychological Review from Injury through Recovery. Clin Neuropsychol. 2008; 22: 769 - 800. https://doi.org/10.1080/13854040701543700

57. Cooksley R, Maguire E, Lannin NA, et al. Persistent symptoms and activity changes three months after mild traumatic brain injury. Aust Occup Ther J. 2018; 65: 168 - 175. https://doi.org/I0.I I I I/I440-1630.12457

58. Sady M, Vaughan C, Gioia G. School and the concussed youth: recommendations for concussion education and management. Phys Med Rehabil Clin N Am. 20II; 22: 701 - 19, ix. https://doi.org/10.1016/j.pmr.201 I.08.008

\section{AUTHOR CONTRIBUTIONS}

Faye Sinnett: Primary contributor. Developed the research idea, conducted the research and developed the clinical guidelines.

Denise Franszen: Assisted with the development and final writeup of the article.

Corresponding Author

*Faye Sinnett

Email: faye.sinnett@wits.ac.za 